\title{
Comunicação pública na promoção dos direitos de crianças e adolescentes
}

\author{
Ana Márcia Diógenes Paiva Lima \\ Mestre; Faculdade 7 de Setembro \\ anamarcia83@gmail.com \\ Inês Silvia Vitorino Sampaio \\ Doutora; Universidade Federal do Ceará \\ ines@ufc.br
}

\section{Resumo}

Este artigo analisa a comunicação pública, que visa à promoção do acesso ao direito de crianças e adolescentes, em um município cearense, certificado em todas as edições do projeto Selo UNICEF Município Aprovado. A análise esteia-se em Zémor (2003) e Brandão (2009), para pensar a comunicação pública, e em Faoro (2001), Freyre (2004) e DaMatta (2001), para compreender aspectos da cultura política brasileira. A pesquisa consistiu na realização de grupos focais com adolescentes e adultos, além de entrevistas em profundidade com gestores e agência de comunicação. Identifica-se, recorrendo à metodologia interpretativa, o fato de que o município avançou na oferta e qualidade da comunicação para os direitos, mas, como outros municípios brasileiros, necessita conhecer melhor as demandas da população, adequar as mídias aos propósitos de sua política pública e promover a participação de crianças e adolescentes na produção de comunicação.

\section{Palavras-chave}

Comunicação pública. Esfera pública. Política pública. Direitos. Crianças e adolescentes.

\section{Introdução}

O Brasil vive há mais de duas décadas um período de conquistas dos direitos humanos nas mais diversas áreas. A Constituição de 1988 (BRASIL, 2009) estabeleceu o reconhecimento do município como membro da Federação, ao lado da União, estados e 
Distrito Federal. Com esse avanço organizacional, o município adquiriu amplitude política e econômica, tornando-se, em parceria com os estados e a União, responsável pela promoção de políticas públicas para os setores básicos.

Essa descentralização proposta pela Carta Magna, em princípio, deveria permitir uma gestão mais adequada à realidade de cada município, com a implementação de políticas públicas capazes de considerar as singularidades locais em um país com tamanha diversidade. Entendemos, contudo, que existe um défice importante no acesso dos cidadãos às informações básicas para o exercício da cidadania, portanto um problema na comunicação pública a fazer com que algumas políticas voltadas à promoção de direitos, como será analisado ao longo deste artigo, ainda não sejam de conhecimento da sociedade.

Ao proceder a um estudo recente acerca da responsabilidade de quatro municípios do Estado do Ceará em promover um fluxo informativo e comunicativo com seus cidadãos orientados por planos de comunicação, Diógenes $(2009)^{1}$ observou alguns descompassos na forma pela qual a informação sobre serviços públicos é divulgada junto à população em municípios cearenses em relação às necessidades expressas pela comunidade.

0 estudo registrou o fato de que a população desses municípios de pequeno porte recebia informações sobre serviços públicos, predominantemente, por meio do contato direto com funcionários públicos, embora preferisse a comunicação via rádio e carro de som. Apesar do baixo custo dessas opções, a maioria das prefeituras optava por pagar pelo espaço em jornais impressos e TVs para falar com seus cidadãos.

Por seu papel destacado na promoção da visibilidade da informação relativa aos direitos, às ações institucionais, à cultura cívica, entre outros, é fundamental que se avalie a importância da comunicação pública para a promoção da cidadania e a garantia dos direitos. A comunicação pública, conforme Pierre Zémor (2003), tem suas finalidades associadas às das instituições públicas. São elas:

a) Informar (levar ao conhecimento, prestar conta e valorizar); b) de ouvir as demandas, as expectativas, as interrogações e o debate público c) de contribuir para assegurar a relação social (sentimento de pertencer ao coletivo, tomada de consciência do cidadão enquanto ator); d) e de acompanhar as mudanças, tanto as comportamentais quanto as da organização social. (ZÉMOR, 2003, p. 76).

\footnotetext{
${ }^{1}$ No estudo Leading through strategic communication - The use of the ACADA Planning Model to promote public communication of children and adolescents rights, Ana Márcia Diógenes (2009) entrevistou 20 cidadãos e quatro prefeitos dos municípios de Horizonte, Redenção, Guaiúba e Maracanaú, no Estado do Ceará.
} 
Compartilhamos, neste aspecto, da concepção expressa no Relatório MacBride ${ }^{2}$, publicado sob o nome Um mundo e muitas vozes - Comunicação e Informação na nossa época, de que a comunicação se configura como um dos direitos humanos, e que "O direito à comunicação constitui um prolongamento lógico do progresso constante em direção à liberdade e à democracia". (UNESCO, 1983, p. 287). Ele compõe, juntamente com o direito à paz, à autodeterminação dos povos, os direitos ambientais e os direitos às minorias, entre outros, o campo dos direitos difusos.

No caso do direito à comunicação, ele tem uma peculiaridade que lhe assegura lugar de destaque entre os direitos e que, muitas vezes, não é devidamente considerada. Trata-se de um direito que é condição para o exercício de outros direitos. Nas palavras de Gentilli (2005, p. 12), “[...] um direito sem o qual o exercício de outros direitos fica prejudicado”. Por isso mesmo, deve ser considerado no mesmo patamar de outros direitos humanos, como saúde, educação e moradia.

Internacionalmente, o reconhecimento da natureza basilar desse direito já consta no Relatório MacBride citado anteriormente, que traz em suas conclusões as noções de que:

[...]; iii. A liberdade de informação - mais exatamente o direito de procurar, receber e difundir informação - é um dos direitos humanos fundamentais e constitui, inclusive, um pré-requisito para muitos outros direitos. [...]; iv. É indispensável que os países formulem políticas nacionais globais de comunicação [...]. Para isso, deveria ser estabelecida uma ampla consulta a todos os setores interessados [...]. (UNESCO, 1983, p. 421).

Então, aí está radicada a importância de conhecer e avaliar como se estrutura a comunicação pública no plano local, o município, como locus fundamental no qual a informação sobre os direitos deve circular. 0 objetivo deste artigo é, assim, analisar a comunicação pública, que visa à promoção do acesso ao direito de crianças e adolescentes em um município cearense, Horizonte ${ }^{3}$, certificado em todas as edições do projeto Selo UNICEF Município Aprovado. De modo mais específico, visa compreender a percepção dos gestores e da comunidade local sobre essa comunicação pública, considerando a sua capacidade de promover: a) o acesso à informação, b) os direitos das crianças e dos

\footnotetext{
20 relatório resulta do trabalho de uma Comissão que, em 1976, em Nairobi (Quênia), foi definida para revisar problemas relacionados à comunicação na sociedade, considerando os avanços tecnológicos no plano mundial.

${ }^{3}$ Horizonte está entre os sete municípios que ganharam todas as seis edições do projeto Selo UNICEF Município Aprovado, no Ceará, uma iniciativa do Fundo das Nações Unidas para a infância, criada no Ceará em 1999, e adotada em 11 estados do Semiárido em 2006, e em nove da Amazônia, em 2009.
} 
adolescentes e c) a participação da comunidade em tais políticas. Investigar a realidade dessa comunicação local, tendo como base os discursos dos envolvidos, é um dos caminhos para melhor compreendê-la e contribuir com as demais administrações municipais brasileiras no que concerne este ponto. Afinal, com uma população de 201,5 milhões de habitantes, divididos em 5.565 municípios, o Brasil tem na comunicação pública local um enorme desafio a ser enfrentado (IBGE, 2010).

Para tanto, foi desenvolvida uma pesquisa qualitativa, recorrendo à abordagem multimetodológica: entrevistas em profundidade 4 com os gestores municipais (prefeito e secretários da Educação, da Saúde e do Desenvolvimento e Inclusão Social), a diretora da agência responsável pela comunicação do Município ${ }^{5}$; e grupos focais ${ }^{6}$ com a comunidade.

No último caso, foram compostos dois grupos focais: um com nove pais e/ou adultos e outro com catorze adolescentes, observando o equilíbrio de gênero em ambos. Como Horizonte possui apenas três distritos, a opção foi de entrevistar moradores da zona urbana. No grupo focal dos adultos, foram utilizados os seguintes critérios de seleção: pais e mães, de bairros variados e da zona rural, trabalhadores e funcionários públicos. O grupo dos adolescentes foi composto de estudantes, de 12 a 18 anos, de escolas públicas e bairros variados. Os grupos focais aconteceram em agosto de 2011.

A análise se baseia em uma abordagem interpretativa, recorrendo a algumas orientações da análise do discurso ${ }^{7}$. 0 objetivo foi cotejar trechos das entrevistas com as reflexões desenvolvidas nos grupos focais, para a compreensão dos discursos em pauta sobre como gestores percebem e conduzem a comunicação pública focada nos direitos de crianças e adolescentes; e de que modo a comunidade qualifica estas informações e as estratégias comunicacionais utilizadas para promover estes direitos no município. Esse é o foco da análise desenvolvida a seguir.

\footnotetext{
${ }^{4}$ Haguette define a entrevista como um "[...] processo de interação social entre duas pessoas na qual uma delas, o entrevistador, tem por objetivo a obtenção de informações por parte do outro, o entrevistado". (HAGUETTE, 1987, p. 86).

${ }^{5}$ Para a identificação dos depoimentos, utilizaremos as abreviações e sigla indicadas: Secretário de Educação (SE), Secretário de Saúde (SS), Secretária do Desenvolvimento e Inclusão Social (SDIS), Diretora da Agência de Comunicação (DA) e Prefeito (P).

${ }^{6}$ Gaskell postula a noção de que entrevistas devem ser individuais, pois focam "[...] experiências individuais detalhadas, escolhas e biografias pessoais" e, grupais, para "[...] assuntos de interesse público ou preocupação comum, por exemplo, política, mídia, comportamento de consumidores [...]" (GASKELL, 2002, p. 78).

${ }^{7}$ Para Eni Orlandi, a "Análise do Discurso visa fazer compreender como os objetos simbólicos produzem sentidos, analisando assim os próprios gestos de interpretação que ela considera como atos no domínio simbólico, pois eles intervêm no real do sentido". (ORLANDI, 2003, p. 26).
} 


\section{Comunicação Pública: ponte para o Estado de Direito}

Cada pessoa vê o mundo de forma única, mas o faz com base em referenciais coletivamente compartilhados e colabora na definição do modo como vê, interpreta e age sobre este mesmo mundo. Considerando que é por meio do acesso à informação que esse processo se realiza, a comunicação pública se configura como um dos caminhos para que se estabeleçam relações e representações compartilhadas entre a sociedade e o poder público.

Como, porém, compreender o que é a comunicação pública? Na perspectiva de Brandão (2009), essa é uma área que abarca uma grande variedade de saberes e atividades, e é um conceito que ainda está em decurso de elaboração. Zémor (2009, p. 225), por sua vez, compreende que "A comunicação pública é, ela própria, uma missão de serviço público". Ele observa que a comunicação pública, na prática,

[...] assume diferentes formas ligadas às missões das instituições públicas. Ela é encarregada de tornar a informação disponível ao público, de estabelecer a relação e o diálogo capazes de tornar um serviço desejável e preciso, de apresentar os serviços oferecidos pela administração, pelas coletividades territoriais e pelos estabelecimentos públicos, de tornar as próprias instituições conhecidas, enfim, de conduzir campanhas de informação e ações de comunicação de interesse geral. (ZÉMOR, 2009, p. 214).

Brandão (2009) classifica a comunicação pública em cinco áreas: conhecimentos e técnicas da área de comunicação organizacional, comunicação científica, comunicação do Estado e/ou governamental, comunicação política e estratégias de comunicação da sociedade civil. Visto que a investigação abordada neste ensaio cuida de aspectos relativos à relação entre oferta e demanda da comunicação pública em um município brasileiro, adotamos como referência analítica prevalente a área da comunicação do Estado e/ou governamental.

Na intelecção de Duarte (2009), um diferencial da comunicação pública é o de centrar o processo no cidadão, "não apenas por meio da garantia do direito à informação e à expressão, mas também do diálogo, do respeito às suas características e necessidades, do estímulo à participação ativa, racional e corresponsável”. (DUARTE, 2009, p. 61).

Esse desafio remete à necessidade de refletir acerca do contexto em que se realiza a comunicação pública e da cultura política na qual esta comunicação está inserida. Como postula Zémor (2009), ao abordar a relação entre o serviço público e a comunicação pública, esta deve se submeter a quatro exigências: informar por dever, assegurar a pedagogia 
atrelada a uma mensagem complexa, incluir a comunicação no processo de identificação e entrega do serviço e contribuir para conferir sentido à vida coletiva.

No conceito brasileiro, os municípios se constituem como espaços favoráveis ao desenvolvimento da comunicação pública, em particular, no que se refere à promoção de direitos? Embora fuja aos objetivos deste artigo dar conta desta resposta, consideramos importante tecer algumas considerações sobre os aspectos da cultura política brasileira que delineiam limites e possibilidades na forma como a comunicação pública se configura entre nós.

Norbert Elias (1994), um dos estudiosos de destaque na abordagem sobre como as pessoas se ligam umas às outras em sociedade, compreende que a natureza das relações entre elas faz com que cada uma componha uma história singular, mas, o "[...] que advém de sua constituição característica depende da estrutura da sociedade em que ela cresce". (ELIAS, 1994, p. 28).

Há um contexto societário, definido social, política e institucionalmente, que compõe a cultura política de um determinado país e colabora com um tipo de entendimento historicamente datado do que seja, por exemplo, o exercício da cidadania. 0 Estado e a sociedade brasileiros trazem marcas profundas da colonização exercida por um Estado monárquico absolutista, que definiu lá e aqui os súditos e seus bens como patrimônios do rei. A sociedade brasileira que se ergueu sobre essas bases carregou o patrimonialismo (FAORO, 2001), o familismo (FREYRE, 2004), a indistinção das esferas do público e do privado (DAMATTA, 2001), entre outros.

0 modelo concentrador de poder se configurou nas fazendas, impactando, segundo Ribeiro (1970, p. 227), “[...] a família, a religiosidade, a nação mesma, como projeção de sua estrutura elementar sobre a ordenação do estado, e do seu papel hegemônico sobre os poderes públicos". Nas palavras emblemáticas de Freyre:

A casa-grande venceu no Brasil a Igreja, nos impulsos que esta a princípio manifestou para ser a dona da terra. Vencido o jesuíta, o senhor de engenho ficou dominando a colônia quase sozinho. 0 verdadeiro dono do Brasil. Mais do que os vice-reis e os bispos. A força concentrou-se nas mãos dos senhores rurais. Donos das terras. Donos dos homens. Donos das mulheres. Suas casas representavam esse imenso poderio feudal. (FREYRE, 2004, p. 38).

Este modelo, por sua vez, influenciou também a urbanização que se seguiu. De acordo com Holanda (1969, p. 105), esse não resultou somente do crescimento das 
cidades, mas também da atração de "[...] vastas áreas rurais para a esfera de influência das cidades", ensejando um "desequilíbrio social, cujos efeitos permanecem vivos ainda hoje".

As marcas do autoritarismo e do arbítrio, muitas vezes até da força, nas negociações de interesses entre setores de variadas escalas hierárquicas de mando e prestígio definiram ainda outra característica que marcou, de forma decisiva, o modo de se fazer política no país: o chamado "jeitinho", que estabelece o trato privado da coisa pública para os familiares, correligionários e afins e priva a expressiva maioria dos seus direitos fundamentais.

Com efeito, Carvalho (2007, p. 30) alerta para a noção de que "A desigualdade é hoje o equivalente da escravidão no Século XIX", e observa que o maior desafio para o Brasil democrático "[...] será conceber e executar políticas que gerem desenvolvimento e, em consequência, reduzam a desigualdade que nos separa e a violência que nos amedronta". Por todo o exposto, acreditamos que se trate de uma questão bem mais complexa do que apenas a promoção do desenvolvimento, que, embora importante, não é garantia de superação da desigualdade e, muito menos, de uma mudança substantiva na cultura política constituída ao longo de séculos. Isso não significa desconhecer que avanços importantes no sentido de redefinir essa tradição tenham deixado de ocorrer, em particular, após a recente democratização do país, em particular, com a Constituição de 1988.

Além das mudanças estruturais no campo das políticas econômicas e sociais voltadas à promoção de uma sociedade mais igualitária no Brasil, é estratégico que este também avance em termos de sua comunicação pública. É necessário que as informações sobre os direitos sociais previstos na Carta Magna realmente cheguem aos cidadãos e passem a ser tratadas como prioridade.

Vale ressaltar que a ausência dessa prioridade no contexto político nacional não decorre de uma incompreensão normativa. 0 entendimento de que o direito à informação é um direito humano está previsto na Constituição brasileira. 0 parágrafo n. $1^{\text {o }}$ do art. 37 define que: "A publicidade dos atos, programas, obras, serviços e campanhas [...] dos órgãos públicos deverá ter caráter educativo, informativo ou de orientação social [...]”. (BRASIL, 2009, p. 19). Além disso, o art. 5 do mesmo parágrafo embasa a visão de políticas públicas de comunicação como o acesso à informação, o direito à informação, interesses sociais e exercício da cidadania. 
Apesar dos avanços na vida sociopolítica brasileira, expressos em marcos legais como a Constituição de 1988 há pouco referida e o Estatuto da Criança e do Adolescente, de 1990 (BRASIL, 1990), a importância do direito à informação como primordial ainda não foi incorporada devidamente à comunicação pública, o que tem relação com os traços dessa cultura política autoritária e patrimonialista, que ainda nos marca profundamente. É o que buscaremos evidenciar na análise a seguir, localizada na experiência de um município, e que consideramos reveladora, ainda que não representativa, de muitos municípios brasileiros.

\subsection{0 município, a comunidade e a visão da comunicação pública}

Horizonte, com uma população de 55.154 habitantes, é um município predominantemente urbano e integra a Região Metropolitana de Fortaleza (IBGE, 2010b). Destaca-se pelo crescimento econômico baseado na indústria e na geração de empregos, e é considerada a quinta cidade ${ }^{8}$ de maior Índice de Desenvolvimento Municipal (IDM) do Ceará, segundo o Instituto de Pesquisa e Estratégias Econômicas do Ceará (IPECE) (IPECE, 2010a).

O crescimento populacional no município foi um dos cinco maiores do Estado entre os anos 2000 e 2010 (IPECE, 2010a). Horizonte é o 8o município, entre os 184 do Ceará, em Produto Interno Bruto (PIB) per capita mais elevado (IPECE, 2012).

Para conhecer como sucede a percepção dos gestores de Horizonte sobre a comunicação pública, objeto deste estudo, as entrevistas realizadas incentivaram que todos se expressassem acerca do significado da comunicação pública. Eles compartilharam as seguintes reflexões:

\footnotetext{
"São as divulgações, as publicidades que o Governo faz." (SE).

"É a comunicação articulada [...], que tem uma função ou uma atribuição pública com seu público específico." (SS).

"É o acesso às pessoas, à comunicação da vida, das coisas que acontecem no seu cotidiano". (SDIS).

"É a comunicação que é feita para mobilizar para a utilização dos serviços." (DA).

"Levar ao conhecimento da comunidade os programas que a gestão oferece, para que saibam o que têm direito". (P).
}

Os depoimentos revelam que alguns restringem a comunicação pública à materialidade dos produtos (peças de comunicação); há quem denote uma visão um tanto 
vaga do acesso à comunicação "da vida" e há pelo menos três afirmações que destacam a natureza ou função pública desta comunicação. Neste caso, essa função pode significar simplesmente a prestação de um serviço, ou trazer a noção mais complexa da promoção de direitos.

Em razão dos posicionamentos dos gestores, é possível identificar, em primeiro lugar, o fato de que não há uma visão clara acerca do que deva ser a comunicação pública no município. Possivelmente, o que ainda os une é a ideia de que a comunicação pública envolve tornar acessível ao público o conhecimento da oferta de determinados serviços, uma compreensão ainda distante da ideia de que a comunicação pública deve estar também comprometida com o propósito de fortalecer os vínculos de pertença e de consciência cidadã, colaborando, assim, para conferir sentido à vida coletiva, como nos alerta Zémor (2009).

Além disso, no discurso dos gestores e agência, o entendimento da comunicação pública está focado na ideia de um caminho de mão única, no qual serviços públicos são prestados, ou é realizada a prestação de contas pelo governo para a população. Não se identifica a mesma ênfase na incorporação da participação da comunidade nesse processo, o que poderia configurar um caminho de mão dupla, que não se limitaria a informar para $a$ comunidade, mas a estimularia a produzir informação pela/com a comunidade.

A questão nos remete a Paulo Freire (1967), que aborda a necessidade de participação política e de inserção na comunidade, para que a democracia se efetive no Brasil, o qual, segundo ele, "[...] nasceu e cresceu sem experiência do diálogo. De cabeça baixa, com receio da Coroa". (FREIRE, 1967, p. 66).

Freire destaca, ainda, que "[...] comunicação é diálogo na medida em que não é transferência de saber, mas um encontro de Sujeitos interlocutores que buscam a significação dos significados". (FREIRE, 1967, p. 69). No caso do município de Horizonte, há que ser observada uma preocupação na busca de estratégias para disseminar informação junto à população, mesmo que exista uma lacuna importante no reconhecimento de que esse público seja promotor de diálogo. Novamente, aqui, é possível identificar traços do autoritarismo na nossa tradição política.

No grupo focal com os adolescentes foi observada a associação da expressão da comunicação pública de maneira mais direta a um meio, produto, ou espaço de comunicação, 
citando: "rádio", "entrevista", "televisão", "jornal", "folheto", "mais cartazes", "programas de rádio" e "palestras".

No grupo dos adultos, a comunicação pública foi associada a sentidos bastante diversos, como: "Viabilizar as informações para a comunidade", "A comunicação pública que todo mundo possa saber, via jornal, carro ou televisão", "É um departamento [...] ligado ao gestor" e "Quando o gestor vem publicamente, diretamente, às pessoas." 0 destaque, neste caso, recai para a ideia de promoção e acesso à informação e para a responsabilidade do gestor neste processo.

Pelo exposto, enquanto os adolescentes relacionaram comunicação pública diretamente à noção de meio, espaço ou produto de comunicação, a maior parte dos adultos relacionou o conceito ao acesso e à promoção ampla da informação, identificando, também, as mídias como instrumentos privilegiados para a sua realização. Nas respostas aparece, ainda, a ideia de atenção à população ("[...] que todo mundo possa saber" ou "o gestor vem diretamente às pessoas").

Contudo, o fato de adolescentes e adultos não associarem claramente a comunicação pública com sentido aos direitos constitui um indício de que esta dimensão relacional entre comunicação e cidadania não está sendo enfrentada a contento. Vale destacar, como postula Duarte (2009, p. 67), que as barreiras na comunicação não se ligam apenas à falta de instrumentos ou da informação em si, mas à "[...] dificuldade em ajudar o interessado a descobrir que ela existe, onde está, como acessá-la e como utilizá-la para aumentar o seu conhecimento e capacidade de agir". Na contextura nacional, a superação dessas barreiras remete, ainda, à compreensão de que o acesso à informação não constitui favor, tampouco privilégio de amigos, mas direito.

Na sessão a seguir, analisamos outros pontos das entrevistas e grupos focais com o fito de compreender, na visão dos integrantes desta pesquisa, o modo como o município sob exame planeja, executa e avalia sua comunicação pública sobre os direitos de crianças e adolescentes.

\section{Comunicação Municipal: a análise dos gestores e da comunidade}

O direito de um cidadão ter direitos - tal como proposto pela filósofa Hannah Arendt (2004) - depende da eficiência e da eficácia da comunicação pública. Essa é fundamental 
para que a cidadania realmente possa ser exercida por meio do acesso à informação sobre o direito, além da oferta do serviço correspondente a cada direito e da qualidade na prestação deste serviço.

Nesse sentido, de modo a analisar a natureza da comunicação pública desenvolvida no município de Horizonte, buscamos identificar junto aos grupos sociais já indicados como se dá o acesso à informação, se este se revela satisfatório e como interfere no cotidiano dos seus cidadãos.

Para efeito de sistematização, os depoimentos dos três segmentos foram agrupados em torno de alguns aspectos relativos ao acesso à comunicação pública; à natureza da comunicação pública: direito que gera direitos? e ao desafio da participação no estabelecimento da comunicação pública. Estes pontos serão desenvolvidos a seguir.

\subsection{0 acesso à comunicação pública}

Em seu depoimento, o Prefeito relatou que o município usa com frequência as emissoras de rádio locais e jornais de maior circulação para se comunicar com a população. Para ele, a televisão é vista como o meio mais eficiente para promover a comunicação do município, seguido pelo rádio e jornal, nesta ordem. Os secretários destacaram como meios preferidos os carros de som, o rádio, a emissora de TV do município vizinho, jornais regionais e/ou de grande circulação, uma revista sobre o aniversário do município, além de rádios escolares e a página da cidade na internet.

Nas entrevistas com os gestores, a dicção "comunicação direta", ou seja, face a face, foi usada com frequência. Eles observaram ser comum e eficiente o fato de que técnicos de determinadas áreas, principalmente os agentes de saúde e os professores, sejam os próprios difusores de informações para públicos com os quais têm contato mais direto.

A maioria dos adolescentes avaliou essa modalidade de comunicação direta como uma estratégia eficaz para alcançar a comunidade, principalmente no caso dos agentes de saúde e dos professores na escola. Uma participante salientou, porém, que a comunicação também se estabelecia pelo rádio. Contudo, um deles acrescentou ter tido acesso a informações "pelo carro de som que passou na minha rua". O debate sobre esse aspecto revelou, por unanimidade, a escola como o local privilegiado de acesso às mais variadas informações, 
além de sinalizar o interesse por uma comunicação mais próxima e mais associada às relações face a face ${ }^{9}$.

Quando sugerida a discussão entre os adolescentes sobre qual a melhor forma que o município poderia adotar para se comunicar com eles, a preferência do grupo voltou-se para os programas nas rádios escolares e as redes sociais da internet. Quatro adolescentes informaram que onde estudavam havia rádio escolar ${ }^{10}$, mas criticaram falhas no funcionamento e apontaram a necessidade de uma programação mais equilibrada entre música e informação. Uma estudante ponderou que na sua escola a rádio não tocava só música, e que "eles liberam pra dar recado pra amigos", destacando também o lugar da rádio escolar nos processos de sociabilidade. Esse potencial da rádio escolar de reunir informação, entretenimento e se constituir, ao mesmo tempo, como um espaço de sociabilidade, sinaliza que esta forma de comunicação deve ser valorizada na comunicação pública sobre os direitos de crianças e adolescentes.

Em relação às novas mídias, oito adolescentes disseram que a escola tem internet, mas a metade reclamou da falta de uma pessoa responsável pelo laboratório, o que inviabiliza, com frequência, o uso dos computadores, uma realidade que não é incomum em muitos municípios brasileiros. Apenas dois adolescentes no grupo pesquisado conheciam o site da Prefeitura e, ainda assim, não o identificaram como espaço no qual pudessem buscar informações para a sua faixa de idade.

Dentre as ações da Prefeitura, o projeto mais tangível na memória dos adolescentes foi o Beija-Flor, por meio do qual o Município articula suas políticas públicas ${ }^{11}$, estando, assim, em maior evidência. Na área da saúde, recordaram também da campanha contra a paralisia infantil ${ }^{12}$, que souberam por carro de som, rádio e pela emissora de TV do município vizinho.

No que concerne aos espaços para divulgação de ações de atendimento para crianças e adolescentes, além do projeto Beija-Flor, a instituição mais citada foi o Conselho Tutelar,

\footnotetext{
${ }^{9} \mathrm{O}$ avanço no acesso às novas mídias merece ser investigado para identificar se houve algum deslocamento na tendência identificada na época da realização do grupo focal.

${ }^{10}$ A Secretaria de Educação, atualmente, tem rádios escolares em dez escolas, sendo seis da zona urbana e quatro da zona rural, dotadas de mesa de som e autofalantes.

11 O Projeto Beija-Flor foi criado em 2009, com o objetivo de promover a integração e a articulação intersetorial na gestão pública de Horizonte, estimulando os profissionais a se articularem para a realização conjunta de projetos nas secretarias afins (HORIZONTE, 2010).

12 As campanhas convidativas para vacinação em massa, como a de paralisia infantil, foram citadas com frequência quando se abordava memória de campanhas de comunicação. Essas campanhas, geralmente, são criadas pelo Poder Público Federal e o material da divulgação repassado para as esferas estadual e municipal; não são criadas em nível municipal.
} 
seguido pela Ouvidoria, Prefeitura, Centro de Referência da Assistência Social - CRAS ${ }^{13}$, Centro Cultural e escolas.

Já quando estimulados por meio da exibição de campanhas produzidas pela Administração Municipal, demonstraram conhecer peças como Passaporte "Saúde Adolescente", panfletos, folders e cartazes sobre trabalho infantil, festivais de talentos especiais e carnaval responsável. 0 acesso a esses materiais se deu, prioritariamente, na escola, no centro cultural, nos postos de saúde e no hospital.

Quanto aos adultos, estes revelaram valorizar mais a comunicação quando transmitida por meio do rádio e da televisão. Um morador da zona rural problematizou que os carros de som divulgavam mais inaugurações do que notícias, fato indicativo de que estes meios poderiam ser mais bem utilizados, principalmente nas áreas remotas, uma vez que a zona rural dos municípios brasileiros é menos adensada populacionalmente e dispõe de menos recursos tecnológicos para receber comunicação por internet e, às vezes, até por televisão. Eles, ainda, criticaram a comunicação face a face; alguns classificaram a comunicação feita pelo município como precária, pois limitada à atuação dos agentes de saúde e a alguns informes pelo rádio; outros propuseram, também, que fossem criadas uma rádio e uma TV locais, mais acessíveis à comunidade.

\subsection{A natureza da comunicação pública: direito que gera direitos?}

Tanto no grupo focal dos adolescentes como no dos adultos, ficou evidenciada a percepção de que a comunicação é um direito humano que contribui para o acesso a outros direitos. Vários adolescentes fizeram questão de dizer que a comunicação "contribui" para outros direitos, além disso, um dos adolescentes observou que "as comunicações estão mudando muito a vida das pessoas". Já no grupo de adultos, apenas uma das mães destacou esse conceito, recebendo a concordância de outro integrante ao colocar comunicação como um direito fundamental: "todo mundo tem direito de saber o que se passa dentro da cidade em que você vive [...], a informação é fundamental".

Ao expressarem seus entendimentos sobre comunicação pública, os adultos, na sua maioria, relacionaram a expressão à transmissão de informação da Administração do

\footnotetext{
13 É uma unidade pública que oferta serviços e ações de proteção básica, atuando como principal porta de entrada do Sistema Único de Assistência Social (SUAS) (BRASIL, 2013).
} 
Município para o público, a exemplo de: "passar um informativo ao público", "Informar para o outro" e "Viabilizar as informações para a comunidade".

Já entre os adolescentes, nove dos 14 entrevistados associaram comunicação pública a um meio ou a um produto de comunicação, utilizando termos e expressões como: "rádio", "entrevista”, "televisão", "jornal”, "folheto", "mais cartazes", "programas de rádio", "palestras", e "mais espaços para os adolescentes debaterem algumas coisas". Os espaços para debate sinalizam o interesse em participar, reforçando a importância de uma comunicação de mão dupla.

Ao mesmo tempo em que reconhecem a comunicação como geradora de acesso a outros direitos, os adolescentes indicam o que pode ser feito de imediato no município em que vivem, para que possam se apropriar de informações sobre direitos - a exemplo da realização de mais programas de rádio, palestras dos conselheiros tutelares nas escolas e, até mesmo, da disponibilização de exemplares do Estatuto da Criança e do Adolescente na biblioteca das escolas.

Para a comunicação avançar no município e fortalecer a noção de direitos, os adultos destacaram a necessidade de melhorar a utilização do rádio e da televisão com programas locais, assim como a publicação de um jornal impresso com as datas dos eventos e da matrícula nas escolas, a ampliação do serviço de carro de som para atingir todo o município e, ainda, uma secretaria de comunicação.

Nas entrevistas com os gestores municipais ficou evidente que o entendimento da comunicação pública ainda permanece muito preso à óptica da comunicação como estratégia de divulgação, que prevalece sobre a ideia da comunicação como política pública, no sentido de um direito que dá acesso a outros direitos.

Entre os depoimentos dos gestores, apesar do reconhecimento de que a comunicação é fundamental para a conquista e garantia da cidadania, foi assumida a noção de que isso "não acontece na maioria dos espaços de comunicação que existem". Observaram, ainda, que a comunicação se direciona, em sua maioria, para informações como oferta de equipamentos esportivos e vagas em escolas e centros infantis.

Os gestores também foram questionados sobre como Horizonte, em cada área de atuação, poderia melhorar as condições para que a população exercesse seus direitos, e se já havia algum plano para esta melhoria se efetivar. A ideia era buscar identificar se eles conferiam à comunicação pública um lugar de destaque. 
O Prefeito destacou a ideia de que, na sua gestão, ainda havia muito a melhorar na área da saúde, reconhecendo que "muito já foi feito, mas ainda tem muito a ser feito.". Ele apontou vários avanços na educação como a ampliação do acesso à escola, a qualidade da educação e infraestrutura, mas ressalvou que ainda poderia ensejar mais oportunidades de melhorias, como ter todas as escolas no sistema de tempo integral, garantindo, pela jornada ampliada, mais tempo de atendimento às crianças e adolescentes.

É interessante identificar o fato de que, embora a comunicação pública tenha sido vista pelo gestor na seção dois como mediação para levar conhecimento à comunidade, esta não foi citada como uma política pública que pudesse contribuir para a melhoria das demais áreas, o que pode indicar que a comunicação não é vista, na dinâmica de sua implementação, como prioridade para a efetivação de outros direitos.

Entre os secretários, a comunicação pública, por regra geral, também não foi mencionada como recurso para melhorar a gestão de suas pastas. 0 Secretário de Educação destacou que sua meta de melhoria era universalizar a educação infantil desde a creche, e a Secretária do Desenvolvimento e Inclusão Social enfatizou a conclusão de um novo prédio e a possibilidade de atender mais cidadãos, ensejando mais benefício em relação aos direitos. Uma exceção, no concernente a esse entendimento, veio do Secretário de Saúde, que afirmou estar mantendo, na época, um entendimento com a agência de comunicação para que fosse criada uma estratégia de comunicação que facilitasse à comunidade compreender melhor o Sistema Único de Saúde - SUS ${ }^{14}$.

As proposições dos gestores sobre o que poderia melhorar para que a população exercesse os seus direitos, em sua maioria, não evidenciam uma compreensão da comunicação como um direito que dá acesso a outros direitos. No entanto, embora não se possa concluir sumariamente que os adultos avançaram mais nessa percepção ao demandarem a criação de uma secretaria para pensar a comunicação do município, eles se posicionam na busca de uma instância que promova planejamento e acompanhamento de ações que atue na implementação de direitos, como é o caso de secretarias mais tradicionais, como a de Educação, Saúde e Assistência Social15.

\footnotetext{
${ }^{14}$ O Sistema Único de Saúde, criado em 1988, tornou o acesso à saúde direito de todo cidadão.

15 Não discutimos aqui o mérito da proposta, mas a compreensão da importância conferida pelos adolescentes à comunicação pública.
} 
O tema do trato político e público da comunicação é enfatizado por Zémor (2009, p. 230), ao reconhecer que "o desafio se remete, para além da comunicação sobre os direitos e deveres do cidadão, à classe política e aos responsáveis públicos".

\subsection{O desafio da participação para elaborar a comunicação pública}

Indagados sobre oportunidades que o Município oferecia para a produção de comunicação para/com adolescentes, menos da metade dos adolescentes se posicionou. Três deles mencionaram ser incentivados a produzir jornal na escola onde estudavam; enquanto outro observou que: "o projeto que eu participo eles passam às vezes nas reuniões que a gente faz para pegar as opiniões também". Os depoimentos dos adolescentes - a exemplo de "na escola tem uma rádio que você pode mandar qualquer notícia" e de "tem um jornal que é para escrever texto" - trazem evidências de que haver um espaço que atenda às demandas próprias desta fase faz com que haja um envolvimento maior por parte deles, inclusive quando são tratadas de questões da comunidade.

Vale destacar a noção de que eles foram unânimes ao asseverar que nunca foram entrevistados a respeito de como preferiam ser informados sobre os serviços públicos. Apenas um entrevistado comentou: "Eu conheço uma menina da minha escola que já foi escutada sobre isso". Esse é um dado revelador da necessidade de que a comunicação pública, em especial relativa aos direitos de crianças e adolescentes, escute o que eles têm a dizer e crie e/ou apoie iniciativas que envolvam a participação deles no produto da comunicação.

Entre os adultos, uma participante indicou o projeto de rádio escolar como um espaço de produção comunicacional com os adolescentes, ao que os outros aquiesceram. Sobre esse tema cabe destacar que, durante as entrevistas com os secretários, eles citaram outras oportunidades de produção de comunicação pela comunidade, como: jornais escolares em 20 das 43 escolas e centros infantis ${ }^{16}$ e uma Rede de Proteção da Criança e do Adolescente, que tem como um dos objetivos criar possibilidades para que o jovem se comunique. A considerar, contudo, o nível de desconhecimento de algumas dessas iniciativas pelos entrevistados, configuram-se como ações de pouca envergadura e/ou com ínfimo destaque na comunicação pública do lugar.

\footnotetext{
${ }^{16}$ Segundo a Secretaria de Educação, o Município tem 43 escolas, sendo que 15 são centros de educação infantil. Do total, 17 escolas e quatro centros de educação infantil estão na zona rural.
} 


\section{Considerações finais}

Os avanços na governança do modelo federativo brasileiro que permitiram a descentralização e a municipalização de serviços essenciais de saúde, educação e proteção, resultam-se fundamentais para a consolidação da democracia no país. Nesse âmbito, a Constituição Cidadã de 1988 e o Estatuto da Criança e do Adolescente (1990) consolidam, no plano normativo, a compreensão de uma sociedade cidadã comprometida com a defesa e promoção dos direitos de crianças e adolescentes.

Essa cultura política democrática, que ainda está em elaboração, convive e disputa com a tradição autoritária que modelou secularmente a história do país e faz com que a comunicação pública nos municípios brasileiros esteja marcada por esse tensionamento. No diálogo com gestores, agentes de comunicação e a comunidade do município de Horizonte, foi possível identificar o que vem na sequência.

1. No concernente à compreensão do sentido da comunicação pública dos gestores, prevalece a ideia de que esta envolve tornar acessível ao público o conhecimento da oferta de determinados serviços. 0 entendimento de que ela deve se voltar também a fortalecer os vínculos de pertença e de consciência cidadã não auferiu o mesmo destaque. Já os adolescentes relacionaram comunicação pública diretamente à noção de meio, espaço ou produto de comunicação, enquanto a maior parte dos adultos relacionou o conceito ao acesso e à promoção ampla da informação, identificando, também, as mídias como instrumentos privilegiados para a sua realização. 0 fato de adolescentes e adultos não associarem, contudo, a comunicação pública claramente à noção de direitos, constitui um indício de que esta dimensão do vínculo entre comunicação e cidadania não é enfrentada devidamente.

2. No que se refere ao acesso à comunicação pública, adultos e adolescentes reconheceram a eficácia da comunicação direta neste aspecto, ou seja, eles reconheceram ter tido acesso a informações variadas por meio dos agentes de saúde e dos professores, mas demandam meios formais de comunicação no plano local. A TV, o rádio e os jornais destacaram-se na preferência dos gestores como instrumentos da comunicação pública no município. Dentre eles, o rádio também 
foi destaque na fala dos adolescentes, em especial, as rádios escolares. Este potencial da rádio escolar em reunir informação, entretenimento e se constituir, ao mesmo tempo, como um espaço de sociabilidade, sinaliza para a ideia de que este tipo de comunicação deve ser valorizado na comunicação pública sobre os direitos de crianças e adolescentes. A possibilidade do acesso à comunicação pública via internet também foi valorizada pelos adolescentes, que questionaram, contudo, a ausência de pessoal qualificado nos laboratórios das escolas. É importante ainda destacar a ideia de que estratégias antigas, como o uso do carro de som, têm seu público, e poderiam ser mais utilizadas, principalmente na zona rural. Em termos de espaço físico, o Centro Cultural e a Escola se destacaram como privilegiados na promoção do acesso às informações, revelando a política bemsucedida em espalhar informação em locais intensamente frequentados e atraentes para o segmento pretendido. 0 destaque conferido ao Projeto Beija-Flor pelos entrevistados revela, ainda, que a articulação das políticas de comunicação em torno de um eixo comum pode representar um impacto positivo na comunicação pública.

3. Em relação à natureza da comunicação pública pautada na noção de direito que gera direitos, é possível divisar no discurso de adolescentes e adultos o argumento de que estes valoram a comunicação como um direito humano que pode contribuir para o acesso a outros direitos. Os adolescentes apontaram demandas que poderiam impactar seus direitos, como mais programas de rádio, palestras de conselheiros tutelares e Estatutos da Criança e do Adolescente na biblioteca escolar. Apesar de os gestores destacarem a comunicação como fundamental para a conquista e garantia da cidadania, esta não foi citada como política pública que pudesse contribuir para a melhoria de demais áreas da Gestão Pública, o que pode indicar que a comunicação ainda não é vista como relevante para a efetivação de direitos.

4. No que se refere à participação na elaboração da comunicação pública, em especial àquela relativa à promoção dos direitos de crianças e adolescentes, malgrado a experiência dos jornais e rádio escolares, o fato de que nenhum adolescente do grupo tenha sido ouvido sobre este tipo de comunicação evidencia uma falha grave no processo de escuta e valorização do que eles têm a dizer. Seus 
depoimentos evidenciam que, se houver um espaço que atenda às demandas próprias dessa fase, eles se envolverão. A considerar, ainda, o nível de desconhecimento das iniciativas citadas por gestores pelos entrevistados, demonstra que estas iniciativas são consideradas como ações que possuem pouca envergadura e/ou que ainda não ganharam o devido destaque na comunicação pública do lugar.

As conclusões deste estudo, indicadas há pouco, têm como base o município de Horizonte, uma vez que este foi o locus analisado, mas é importante salientar que podem ser consideradas por vários outros municípios brasileiros.

Se, como sociedade democrática que somos, reconhecemos que a comunicação é um direito que gera direitos, precisamos avançar no enfrentamento da tradição autoritária que nos formou e fortalecer a ideia de que o mais básico deles é o direito à informação, que não constitui favor, tampouco privilégio de alguns. Se estamos tratando de política de comunicação, não podemos concebê-la e administrá-la como um caminho de mão única seria mesmo comunicação? - No entanto, temos o desafio de incorporar a participação do público em sua elaboração. Se o assunto, enfim, é comunicação pública, precisamos avançar na construção dos sentidos coletivos que nos definem como povo e nos constituem como cidadãos.

\section{Referências}

ARENDT, Hannah. A condição humana. 10. ed. Rio de Janeiro: Forense Universitária, 2004.

BRANDÃO, Elizabeth Pazito. Conceito de comunicação pública. In: DUARTE, Jorge. (Org.). Comunicação pública: estado, mercado, sociedade e interesse público. 2. ed. São Paulo: Atlas, 2009. p. 1-33.

BRASIL. Constituição da República Federativa do Brasil (1988). Brasília: Senado Federal, Subsecretaria de Edições Técnicas, 2009.

BRASIL. Lei no 8.069, de 13 de julho de 1990. Brasília, 1990. Disponível em: <http://www.planalto.gov.br/ccivil_03/Leis/l8069.htm>. Acesso em: 15 abr. 2014.

BRASIL. Ministério do Desenvolvimento Social. Centro de Referência de Assistência Social. 2013. Disponível em: <http://www.mds.gov.br/assistenciasocial/protecaobasica/cras>. Acesso em: 19 mar. 2013. 
CARVALHO, José Murilo de. Fundamentos da política e da sociedade brasileiras. In: AVELAR, Lúcia; CINTRA, Antônio Octávio (Org.). Sistema político brasileiro: uma introdução. 2. ed. São Paulo: UNESP, 2007. p. 19-31.

DAMATTA, Roberto. 0 que faz o Brasil, Brasil? Rio de Janeiro: Rocco, 2001.

DIÓGENES, Ana Márcia. Leading through strategic communication: the use of ACADA Planning Model to promote public communication of children and adolescents' rights. 2009. Monografia (Curso de Aperfeiçoamento) - UNICEF Leadership Development Initiative, Gordon Business Institute, University of Pretoria, Pretória, 2009.

DUARTE, Jorge. Instrumentos de comunicação pública. In: DUARTE, Jorge (Org.). Comunicação pública: estado, mercado, sociedade e interesse público. 2. ed. São Paulo: Atlas, 2009. p. 59-71.

ELIAS, Norbert. A sociedade dos indivíduos. Rio de Janeiro: Jorge Zahar, 1994.

FAORO, Raymundo. Os donos do poder: formação do patronato político brasileiro. 3. ed. São Paulo: Globo, 2001.

FREIRE, Paulo. Educação como prática da liberdade. Rio de Janeiro: Paz e Terra, 1967.

FREYRE, Gilberto. Casa-Grande e Senzala: formação da família brasileira sob o regime da economia patriarcal. 49. ed. São Paulo: Global, 2004.

GASKELL, George. Entrevistas individuais e grupais. In: BAUER, Martin W.; GASKELL, George (Org.). Pesquisa qualitativa com texto, imagem e som: um manual prático. Petrópolis: Vozes, 2002. p. 64-89.

GENTILLI, V. Democracia de Massas: jornalismo e cidadania. Porto Alegre: Edipucrs, 2005. (Coleção Comunicação).

HAGUETTE, Teresa M. F. Metodologias qualitativas na Sociologia. Petrópolis: Vozes, 1987.

HOLANDA, S. Buarque. Raízes do Brasil. 5. ed. Rio de Janeiro: José Olympio, 1969.

HORIZONTE. Beija Flor. 2010. Disponível em:

$<$ http://www.horizonte.ce.gov.br/rede/texto.asp?id=4\&current=prefeitura >. Acesso em: 25 jun. 2013.

INSTITUTO BRASILEIRO DE GEOGRAFIA E ESTATÍSTICA (IBGE). Censo 2010. 2010.

Disponível em:

http://www.ibge.gov.br/home/estatistica/populacao/censo2010/tabelas_pdf/total_populaca o_ceara.pdf. Acesso em: 30 maio. 2014.

INSTITUTO DE PESQUISA ECONÔMICA DO CEARÁ. Anuário Estatístico do Ceará 2010. 2010a. Disponível em: 
<http://www2.ipece.ce.gov.br/publicacoes/anuario/anuario2010/qualidade/indices.htm>. Acesso em: 30 maio 2014.

INSTITUTO DE PESQUISA ECONÔMICA DO CEARÁ. Ceará em mapas. 2010b. Disponível em: <http://www2.ipece.ce.gov.br/atlas/capitulo2/23.htm>. Acesso em: 30 maio 2014.

\title{
INSTITUTO DE PESQUISA ECONÔMICA DO CEARÁ. A evolução do PIB dos municípios
} cearenses no período 2002-2010. 2012. Disponível em:

$<$ http://www.ipece.ce.gov.br/publicacoes/ipece-

informe/Ipece_Informe_49_20_dezembro_2012.pdf>. Acesso em: 30 maio 2014.

ORLANDI, Eni P. Análise de discurso: princípios e procedimentos. 5. ed. São Paulo: Pontes, 2003.

RIBEIRO, Darcy. As Américas e a civilização: processo de formação e causas do desenvolvimento desigual dos povos americanos. Rio de Janeiro: Civilização Brasileira, 1970.

UNITED NATIONS EDUCATIONAL, SCIENTIFIC AND CULTURAL ORGANIZATION (UNESCO). Comissão Internacional para o Estudo dos Problemas da Comunicação. Um mundo e muitas vozes: comunicação e informação na nossa época. Rio de Janeiro: Fundação Getúlio Vargas, 1983.

ZÉMOR, Pierre. A comunicação pública. In: SILVA, Luiz Martins da (Org.). Algumas abordagens em comunicação pública. Brasília: Casa das Musas, 2003. p. 76-103.

ZÉMOR, Pierre. As formas da comunicação pública. In: DUARTE, Jorge (Org.). Comunicação pública: Estado, mercado, sociedade e interesse público. 2. ed. São Paulo: Atlas, 2009. p. 214-245.

\section{Public communication in the advocacy of rights for children and youth}

\begin{abstract}
This paper analyzes how public communication can promote access for children and youth to their rights. It was made in a municipality of the state of Ceará, Brazil, that won all editions of the UNICEF Seal of Approval. The analysis is based on the works of Zémor (2003) and Brandão (2009) in order to discuss public communication, and Faoro (2001), Freyre (2004) and DaMatta (2001) concerning the comprehension of some aspects of the Brazilian political culture. The research was composed by focus groups with teenagers and adults, as well as depth interviews with government officials and communication agencies. Applying the interpretative method for data analysis, it was
\end{abstract}


identified that the municipality has improved the offering and quality of its communication for the rights, however, similar to other municipalities in the country, it still needs a better understanding of people's demands, so it can develop the media to the purposes of public policies and promote the participation of children and youth in the production of communication.

\section{Keywords}

Public communication. Public sphere. Public policy. Rights. Children and Youth.

Recebido em: 08/09/2015

Aceito em: 30/04/2015 